\title{
Usage of distance and blended learning in educating school librarians
}

\author{
Mihaela Banek Zorica \\ Research and teaching assistant \\ Department of Information Sciences \\ Faculty of Humanities and Social Sciences, University of Zagreb
}

Croatia

\begin{abstract}
Sonja Špiranec
Research and teaching assistant Department of Information Sciences

Faculty of Humanities and Social Sciences, University of Zagreb

Croatia

Nikolaj Lazić

Research and teaching assistant

Department of Phonetics

Faculty of Humanities and Social Sciences, University of Zagreb

Croatia
\end{abstract}

\begin{abstract}
Paper shows the case study of transforming traditional learning environment (based on teacher-centred instruction), to the blended learning environment (based on student-centred instruction) using Open Source Learning Management Systems, like Moodle. Special attention was on the advantages in usage of this tool in educating LIS professionals. Authors try to investigate whether new technologies help and motivate students master the necessary knowledge, especially when applied to the mandatory courses. Differences in motivation and access to the studies between the full-time and part-time students are also compared. Data fo the evaluation have been gathered through numerous satisfaction surveys and interviews with the students of Department of Information Sciences, Faculty of Humanities and Social Sciences, University of Zagreb, both full-time and part-time, as well as through the analysis of the data from the faculty's e-learning system.
\end{abstract}

\section{Introduction}

Since Croatia is a transitional country, it is subject to many changes, in education as well as the economy. Present changes can be observed at all levels of education, from the primary schools to the universities. Their aim is to improve quality and efficiency of education. The central principle of these efforts is to develop lifelong learners with intellectual abilities of reasoning, critical thinking, creative problem-solving, decisionmaking, independent learning and the responsible consume of information. In elementary schools we have implemented Croatian National Educational Standard whose aims correspond to the objectives that dominate the educational sector in the EU and are directed at building a knowledge-based society in which the school system is primarily intended to 
prepare pupils for lifelong learning. The Standard was generated as a result of the recognized problems of overloading pupils, inadequate teaching methods and insufficient monitoring and evaluation of the quality of education. In its essence, it acknowledges the importance of relieving pupils from encyclopaedic content and directing them toward creativity, problemsolving abilities and lifelong learning. Reform aspirations in tertiary education, inaugurated by the Bologna agreement, refer to employability, quality assurance, mobility, compatibility and imply lifelong learning as a core concept. These principles have stimulated universities to restructure their curricular offerings and bring them in line with societal needs that predominate in the knowledge economy. This change will enable exchange of both European and Croatian experts and students.

Educational institutions are expected to transform themselves in accordance to the challenges confronting the contemporary society. ICT is perceived as a catalyst for these transformations, which will enable the essential transition from traditional educational paradigms, manifested in instructor-led models (passive knowledge reception, teacher as the «gatekeeper» of information, individual effort) to 21 st century paradigms manifested in student-centered models (problem solving, teamwork, interacting and processing information, active involvement learning, construction and discovery, problem exploration, customized learning).

Institutions of higher education have purposely and seriously begun to position themselves with regard to e-learning. They have made serious efforts to move ahead from the public-relation rhetoric of suggesting innovation towards becoming leaders in drafting vision, policies, and goals with regard to e-learning (Garrison and Anderson, 2003). This is absolutely true and the fact is that countries worldwide are establishing institutions (like UK's Joint Information Systems Committee) and publishing documents and standards that deal with the implementation and improvement of e-learning at the higher education institutions, in giving guidelines as well as evaluate e-learning at universities. Usage of ICT in Croatian educational environment is strongly supported by the government, but there is still a lack of documents and guidelines for implementation and evaluation of e-learning in all the aspects of education (especially in the HE). Nevertheless, Universities and Ministry of Science, Education and Sport are working on the documents and standards that should evaluate and benchmark e-learning programme, and we expect it to be released very soon.

Currently, the largest faculties at University of Zagreb are favouring Moodle and faculties form other universities are following them and the number has grown to 25 higher education institutions i.e. faculties and colleges. Therefore one could say that the Moodle community is Croatia is very strong, and due to that fact Moodle has its translated Croatian version. Especially with the transformation and conciliating university programs with the EU university programs under the Bologna process, the faculties are becoming more aware of the necessity of transformation of teaching regarding the new pedagogical methods and the full usage of the opportunities that ICT offers.

\section{Creating the virtual learning environment}

Today's students entertain, think, learn and grow up in a synthesis of sensory stimuli. The Internet has changed nearly every aspect of how they live, work and learn. The teachercentred instruction that dominated much of primary, secondary and higher education does not 
respond to this new ways of living and learning and requires pedagogical models in which students are allowed to be active participants, leaving teachers the role of facilitators and moderators. This new paradigm leads to the great popularity of the concepts of online learning and e-learning. In pedagogical discussions these and related IT-augmented forms of learning have been labelled as contemporary learning-centred teaching strategies as opposed to traditional, lecture based or teacher-centred strategies. After the initial hype and enthusiasm has calmed down, and oversimplifications regarding the relation between elearning and traditional learning have earned more and more critics, new hybrid approaches, complementing the best features of the traditional and technological paradigm have emerged in higher education.

The Faculty of Humanities and Social Sciences (FHSS) at the University of Zagreb has organization similar to an university - constituted out of 23 Departments, 33 undergraduate programs and around 6100 students of whom the large majority studies at two departments i.e. has two majors. Therefore, a constant problem of time and space for lectures and tutorials is present. But not only had the organizational and infrastructural constraints urged for the creation of new and robust teaching and learning environments. The use of ICT supported learning at the FHSS was perceived as a prerequisite for the achievement of future educational reforms, since most of the students from this Faculty are here to get their teacher's degree. In other words, educational techniques and practices they get acquainted with during their study will ultimately affect their own future educational practice.

In September 2002, we have started a three-year project: Organization of Information and Knowledge in the Electronic Learning Environment (Organizacija informacija i znanja u elektroničkom obrazovnom okruženju - http://infoz.ffzg.hr/oizeoo), funded by the Croatian Ministry of Science, which explored issues within the electronic learning environment. One of the project tasks was to investigate, test and evaluate open source (Learnloop, ZOPE...) and commercial solutions (WebCT, Blackboard...) and decide upon the best solution for the needs of the teaching staff of the Department of Information Sciences and in future the FHSS. Our goal was not to create a self-sustained e-learning program, but a virtual learning environment with the emphasis on blended learning, where the ICT role was to help in dealing with the difficulties of overloaded schedule (problem of time and space) and in facilitating a shift from teacher-centered to student-centered learning.

We have finally chosen free, open-source learning management system MOODLE which was translated into Croatian, customized and implemented for the academic year 2004/2005 under the name OMEGA. The fact that MOODLE is a free, easy-to-use system (i.e. everyone with basic computer literacy can easily use it) with simple and understandable interface was the main reason for implementing it. Furthermore, its large variety of modules and the ability of implementing new modules; SCORM compliance; authentication via LDAP or IMAP (e- mail) user accounts issued by the Faculty; were a major advantage when deciding what products to choose and implement in a large heterogeneous institution like ours is, baring in mind the large number of staff not very familiarized with the idea of using ICT in their teaching. It is also rewarding that we can give back something to the e-learning community - like the Croatian language pack for Moodle, which is now available at the Moodle site.

After spanning more and more courses at the Department of information science and courses of the other departments at the Faculty it has overgrown its departmental character and became a faculty-wide e-learning system. In October 2006, we had 20 departments offering their courses through OMEGA with total number of 180 courses, more than 170 
professors and TAs working on their courses and more than $6 \mathrm{~GB}$ of produced learning and teaching materials. At the beginning of the new academic year we have more than 2500 students enrolled in the courses offered on OMEGA. The number of courses, data, professors and students is increasing and we expect it to grow even more until we have all the courses and students signed in this VLE. In the past year, we had an influx of more than 1000 students, 30 teachers and TAs and the number of courses has nearly doubled. The Department of information science has a largest number of courses - 57, followed by the Department of English with 19 courses, Department of History - 12, Department of Sociology - 11, Department of Croatian language - 10, and so on.

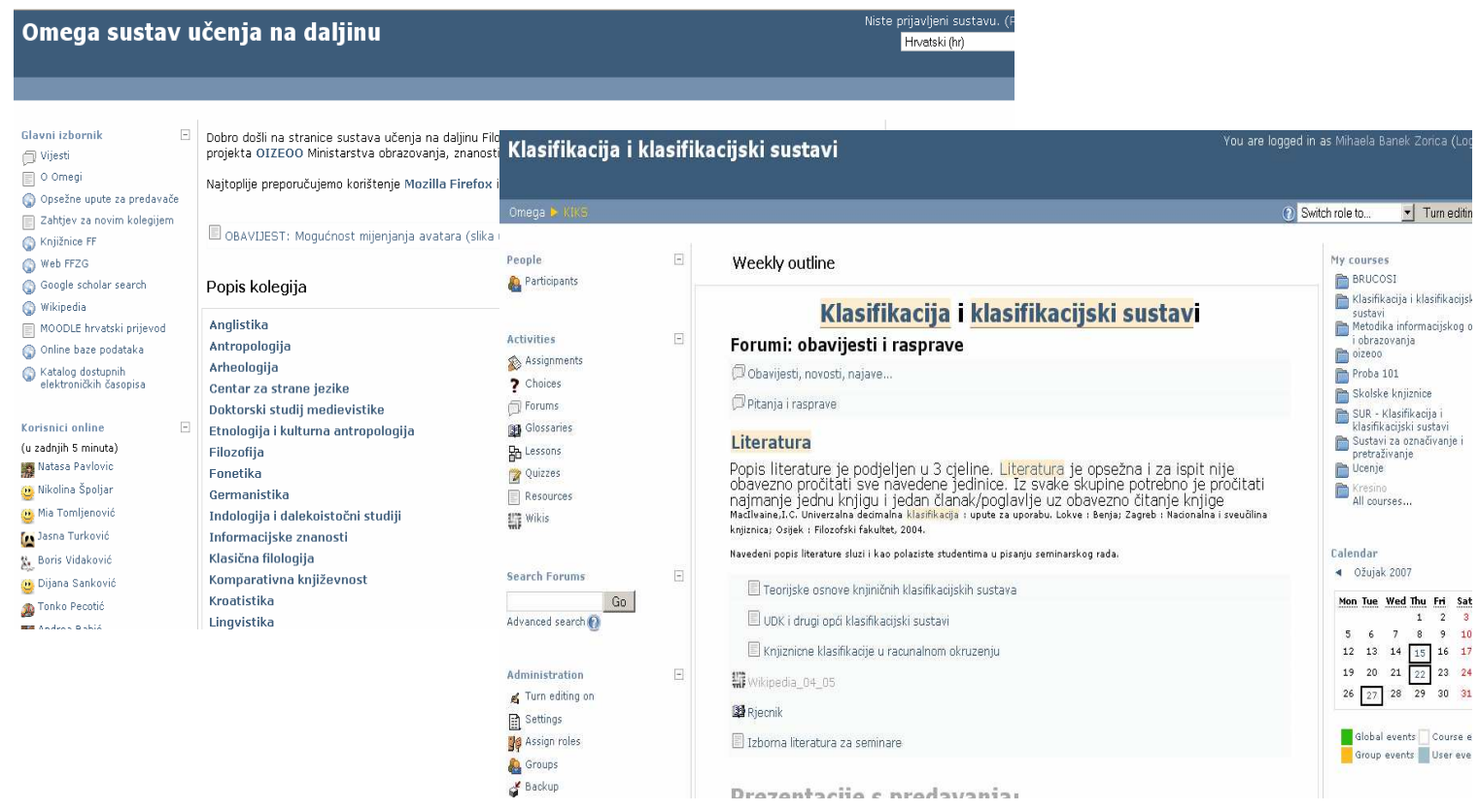

Figure 1. OMEGA VLE

Currently, we are using Moodle v.1.7 with the Croatian language interface and some other minor modifications and customizations, based mainly on end users' requests or needs. If we look at the Moodle module usage statistics, we can see that teachers mostly use following modules: Resource module (3071 instances) - text, html, PDF documents being the majority; Forum module (436 instances) - since there can be more than one forum on the course, and the access to the forums can be customized easily, the teachers are using them both for communication with student body and among themselves; Assignment module (298 instances) - it gives teacher the ability to create assignments that students can do online, offline or via document upload, making the paper submission and grading both easy and transparent (and it is helps saving the forests, too); Quiz module (212 modules) - online quizzes, with numerous capabilities, like random questions, timed sessions, question databases, variety of question types, access control and so on. Thanks to the modular and open-source nature of Moodle, the teachers can use only those modules that they really need at the present time, and if they need some additional type of resource or activity, it can be easily implemented (sometimes in the matter of hours) 


\section{Evaluation of the Virtual learning environment}

The evaluation of the FHSS Virtual learning environment OMEGA was performed on the course taught at the Department of information science - Classification and Classification Systems. It was based on the analysis of students' logs, several surveys and interviews with both full-time and part-time students.

At the Department of information science, Faculty of Humanities and Social Sciences, University of Zagreb, the education of information specialists on the undergraduate level is carried out in two forms, as a full-time and a part-time study. Students that are at the same time enrolled at information sciences studies and some other field of studies are full-time students, while part-time students are already graduated students, working in libraries. Parttime students are those working in libraries, most of them in school or academic libraries.

Course Classification and classification systems consist of lectures and practical exercises and in order to pass the whole course students have to first pass the practical part exam and then proceed to the theoretical exam. This course was prepared and offered to fulltime and part-time students.

Out of 70 users enrolling into the course Classification and classification systems 40 decided to enrol into the blended learning course while 30 decided to follow the traditional classes. The majority of the students enrolled into the blended learning course were student located at distance and had the basic computer literacy. They were offered to attend the lectures and tutorials in classes if needed but were not obliged to do so. Students who attended regular classes were offered to access all the materials on the Omega system. The most interested thing is that three users changed their mind and attended classes combining it with the course on OMEGA, while 10 users of OMEGA found it necessary to attend regular classes. The ratio could be seen in Figure 2. where the interesting thing is that $14 \%$ of students chose the mixture of the two offered ways of enrolling into the course. Full-time students did not have the opportunity to chose between the two modes but were attending regular classes and using OMEGA for the resources, grades or for additional activities and assignments.
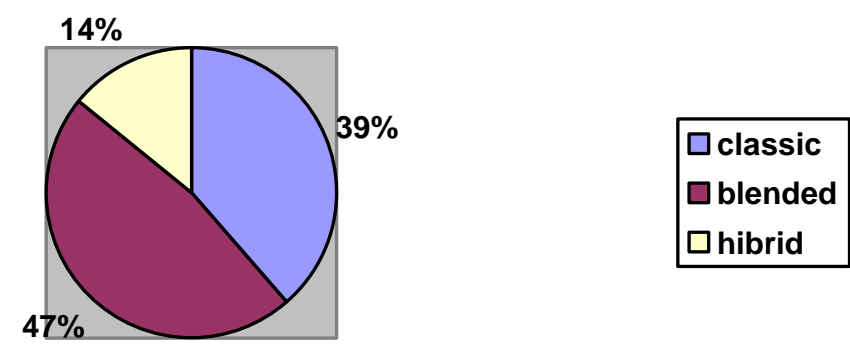

Figure 2. Part-time students attending course

Students of blended learning course were given a period from March to October 2006 for attending and finishing the course while the regular course student were given the shorter period from March to June. They were conditioned to pass at leas the exercise part before they can enrol into another year of studying and finish the whole course before enrolling into 
the next course Indexing and retrieval systems. Out of the 30 traditional course attendees only 20 passed practical and half of them passed also the theoretical part. In the case of the blended course 32 passed the whole course and 8 passed only the practical part. The crucial is that the 25 blended course students passed the whole course until mid July, which is actually before the final deadline. Full-time students were having classes of two semesters, and were getting their grades according to the activities they were doing during the year. Out of 50 fulltime students 40 passed the exam in the first exam period (July) while 10 passed in the second exam period (September). When comparing these numbers with the old ones, we can conclude that this way of teaching is more motivating the students.

In order to see if the students are using resources offered we used student logs (Figure 3., Figure 4.) which showed that students are frequently using resources during their enrolement period. The main difference in these two groups is that the full-time students were having regular classes (and were logging on the OMEGA) with the face-to-face contact with the teacher whom they could then ask for help. Part-time students were mostly using the resources and working on their assignments in the periods of two weeks and if necessary could either e-mail teacher for help or ask for a chat meeting.

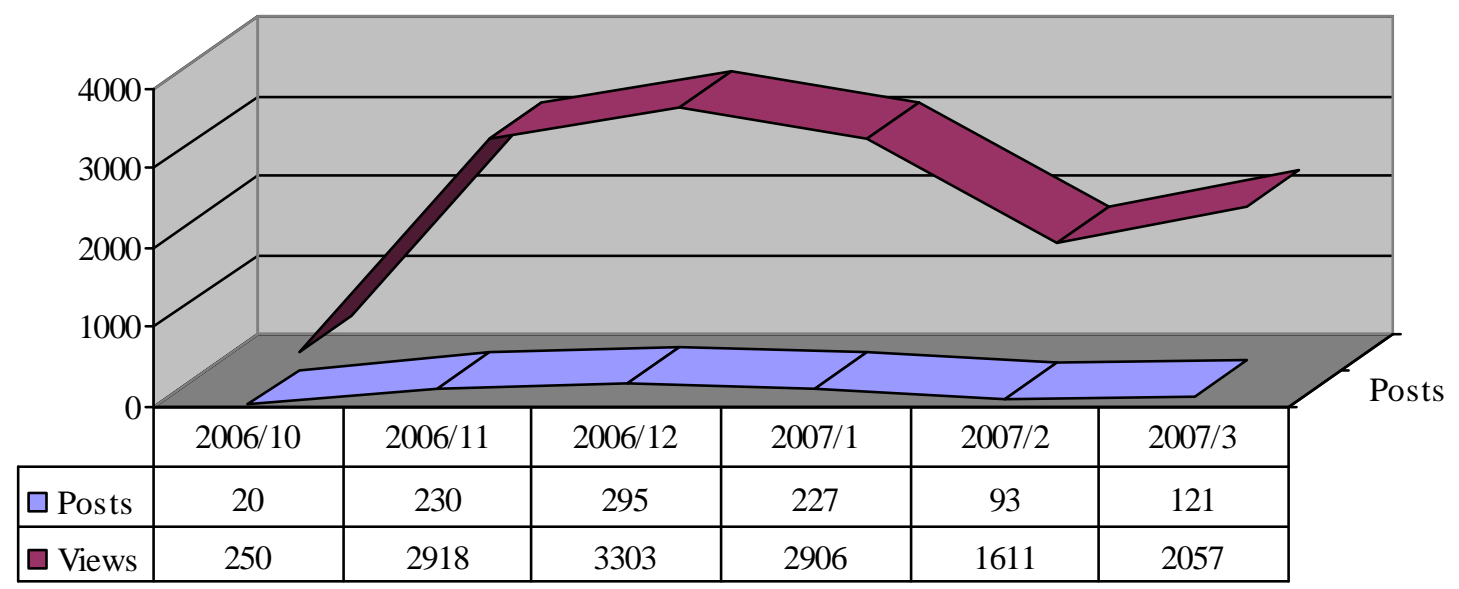

Figure 3. Full time student logs 


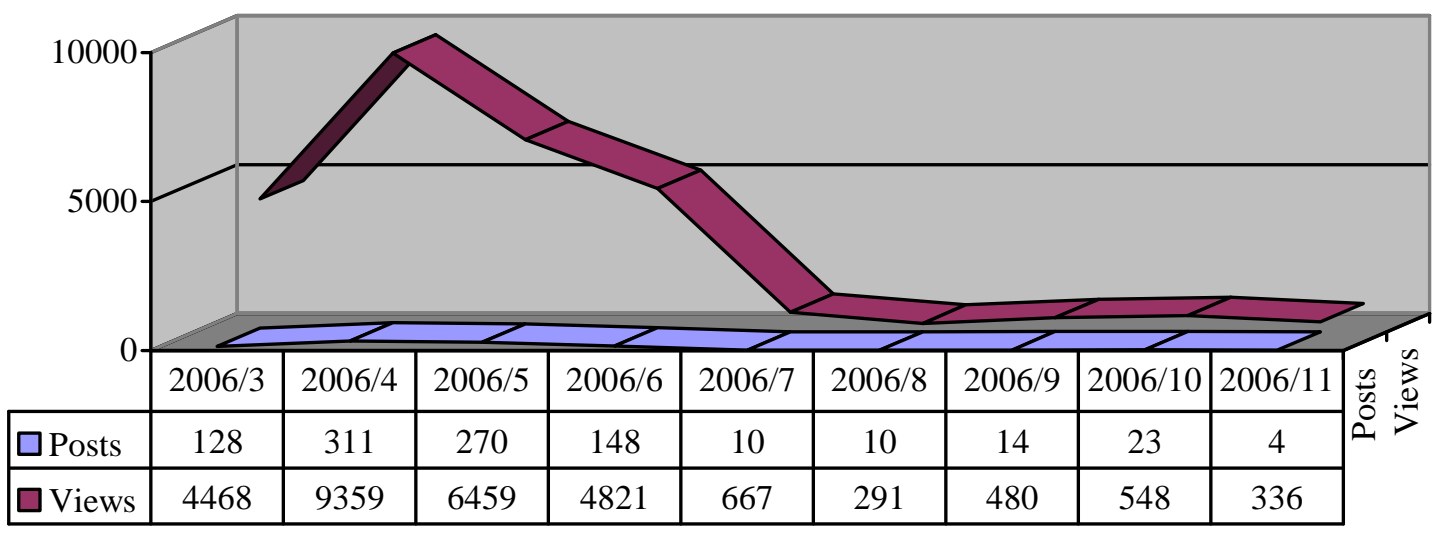

Figure 4. Part time student logs

The student logs show their interest in the subject and resources even in the period when they have break (February). In the Figure 3., one could see a considerably smaller amount of logs comparing to the other months, but still a large amount which shows their interest and constant checking of the resources. Even the number of logs (225 view and 5 post) during the period of hollidays, last week in December and first in January, leads to the conclusion that students are using these resources even in their free time. On the other hand, the numbers of logs of part time students even during the spring break show (July till September) show that some of the students do their assignments in the summer semester when the majority enters the quieter period on their jobs (working as school librarians and having their summer holidays). This is a strong indicator that there would be and interest in summer workshops or courses that could be taught via OMEGA. Furthermore, high numbers of view logs of part-time show that even students that are not enrolled in this course as participants but as guests are looking at the resources offered. These students have chosen to follow the course in traditional environment but still are greatly using these resources and assignments when preparing for their exams or just for the lectures.

Surveys have shown that at the beginning of the course majority of students were not very enthusiastic about the course content or simply did not know what to expect, but the results at the end of the course have shown that their attention has been roused up to the point where they are very interested about the subject (all the students had a shift of at least one level of interest). The content of the course was evaluated as difficult but understandable, especially through the exercises, team work and connection with the real-life examples. Assignments and short quizzes were evaluated positively, even with some of the students commenting that they would encourage the increase of such sort of activities. The majority of students felt that wikis and blogs that they were builidng were most helpful for their exam preparation. The feelings about the recorded lectures were mixed. Part of the students that had access to speed internet connection and broadband were satisfied with it and asked for more resources, while the other part of students who were connecting via modems were experiencing some problems. Although the lectures were compressed as much as possible this indicates that the infrastructure in Croatia is not fully available in all parts. Therefore, in future we will leave these features as optional ones or switch only to podcasts.

Students were asked to evaluate the system and the overall grade was very good $80 \%$ of the students evaluated it as excellent while $20 \%$ evaluated is as very good. They criteria 
that they were evaluating it were on the ease of access, intuitive structure and layout of the system, and the working and up-to-datedness of all the facilities like links, quizzes, videocasts etc. Students also felt that they got all the necessary help form professor and teaching assistant. The minority of students stated that although they never sought teachers support, either because of get it from the discussion forum or because they didn't feel like needing it, they knew that if needed they would get it. Part-time students were much more willing to ask for help either via e-mail, forum or chats, while full-time students were more reserved in asking for teachers help and rather ask their colleagues.

On a general level, evaluation showed that students were satisfied with this new teaching and learning style, firstly because they could prepare themselves for the course assignments and the final exam in time that best suited them. Secondly, they expressed themselves positively about the grading. Unlike the other courses which grade students according to oral or written exams (or both) at the end of the course, the technological capabilities of the system applied allowed more accurate monitoring of student's activities and a more objective and comprehensive evaluation.

The negative side was that although students were stimulated to participate more in discussions on forum, only some actually did. This reflects the situation found in the traditional environment, and the source of this problem would be the lack of the opportunities for a discussion during their primary and secondary education. The majority of students just "lurks" at the discussions and do not feel comfortable to join, although when asked to comment something through assignments all students do so. Therefore, our opinion is that the majority do not feel obliged and motivated to discuss, and if they face a problem would rather discuss it only with the teacher (via e-mails or face-to-face). When comparing full-time and part-time students, part-time students participate in discussions more than the full-time students, which could be connected to their motivation and interest for the studies.

\section{Conclusion}

The evaluation of the transformed educational environment confirmed that following the pattern of blended project-based learning contributed to an increase in students' satisfaction and motivation to actively participate in the course. New environment enabled students to attend regular classes and span their working area independent of space and time but still under the constant supervision. Furthermore, it helped them while working on their courseware assignment - team work project, where they needed place to collaborate and communicate progress in order to write and present their project. The new educational environment enables students to enjoy all the conveniences of technology- based courses and are still allowed to learn within a social context

\section{References}

Allan, B. (2002). E-learning and teaching in library and information services. London : Facet publishing

Garrison, D. R., \& Anderson, T. (2003). E-Learning in the 21st century: A framework for research and practice. Lodon: Routledge/Falmer, 2003 
Garrison, R.D. Kanuka, H. (2004. Blended learning - uncovering its transformative potential in higher education. // The Internet and higher education, 2, 2, , pp. $95-105$.

Rice, W.H. (2006) Moodle : E-learning course development. Birmingham: Packt Publishing.

Omega distant learning system. (2004). http://omega.ffzg.hr/ (accessed 12.10.2006.)

Schuh, K.L. (2004). Learner-centered principles in teacher-centered practices? Teaching and Teacher Education, 20, 8, 833-846.

Todd, R. (2001). Transitions for preferred futures of school libraries: Knowledge space, not information place, Connections, not collections, Actions, not positions Evidence, not advocacy. Paper presented at the 30th Annual conference of the International Association of School Librarianship, Auckland, New Zealand. Retrieved March, 2006, from http://www.iasl-slo.org/virtualpaper2001.html

\section{Biographical Notes}

Mihaela Banek Zorica is a PhD student and research and teaching assistant at the Department of Information Sciences in Zagreb. She published a book on school libraries and several journal and conference papers. Main interest areas are knowledge organization, information retrieval, school libraries and education.

Sonja Spiranec, M.Sc., is a research and teaching assistant at the Department of Information Sciences in Zagreb. For several years she was a a librarian at the Croatian National- and University library where she was actively involved in creating an user education program and information literacy tutorial.

Nikolaj Lazic, Ph.D. is a research and teaching assistant at the Department of Phonetics in Zagreb. His Ph.D. thesis was in text-to-speech synthesis of croatian languages. His main interest areas are natural language processes and information services for the people with dissabillities. 